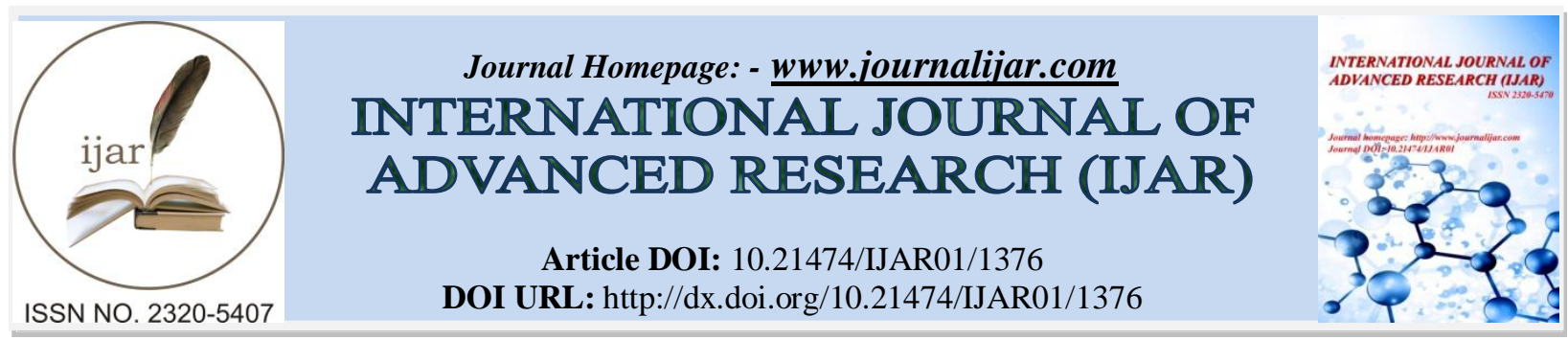

RESEARCH ARTICLE

\title{
COMPARATIVE STUDY ON FOCUS REGULATION AMONG THE ARCHERS AND RIFLE SHOOTERS IN PUNE CITY.
}

\author{
Dr. Swapnil Vidhate ${ }^{1}$ and Mr. Bitam Sadokpam ${ }^{2}$.
}

1. Associate Professor, Department of Physical Education B.V.D.U. Pune. (M.H.) India.

2. Ph.D. scholar B.V.D.U. Pune (M.H.) India.

\section{Manuscript Info \\ Manuscript History \\ Received: 12 June 2016 \\ Final Accepted: 16 July 2016 \\ Published: August 2016}

Abstract

Key words:-

\section{Introduction:-}

In $1200 \mathrm{BC}$ the Hittites and Assyrians shot their bows from chariots, becoming fearsome opponents in battle. They made their bows with tendon, horn and wood and also developed a new re-curved shape. This made their bows shorter and more powerful, making them easier to handle for an archer on horseback. Archery was the favorite sport of the Egyptian pharaohs during the 18th dynasty (1567-1320 BC). Many centuries later, some of the earliest recorded archery tournaments took place during the Zhou (Chou) dynasty (1027- 256 BC) in China. Such events were attended by Chinese nobility. Much later, English writers honored the longbow for famous contributions to their country's victories in the battles of Crécy, Agincourt and Poitiers.

Scorecards will be available at the entrance to each range. Shooters will pick up the official colored scorecard for that day, along with one white "shooter's copy" scorecard which is to be retained by the shooter for their record, at the beginning of each round. The properly completed official colored scorecard must be turned in by the group within fifteen minutes of completion of competition and prior to leaving the range to receive credit for that day's competition. All information on the scorecard must be accurate with all information completely and properly filled in. Information blocks that are incorrect or incomplete will result in a deduction of ten points from their score. Any score changes must be initialed by the scorer and the shooter and no changes may be made to the official score card after the scorekeeper and shooter have signed the scorecard. If a shooter changes his scorecard after it has been signed by the scorekeeper, the shooter will receive a score of zero for that tournament (and toward Shooter of the Year rankings) and will be brought before the ASA Competition Committee for further action.

The Olympic program of the Shooting Sport consists in 15 different events. Olympians compete in nine men's events and six women's events in three different disciplines, with five events for rifles, five for pistols and five for shotguns. The 50m Rifle 3 Positions Men is an International Shooting Sport Federation shooting event, where athletes shoot over a distance of 50 meters / 54.68 yards in kneeling, prone and standing positions, using a 5.6

Corresponding Author:- Dr. Swapnil Vidhate.

Address:- Associate Professor, Department of Physical Education B.V.D.U. Pune. (M.H.) India. 
target is positioned at 0.75 meters above the floor and its total diameter measures 154.4 millimeters. The diameter of the fourth ring is 106.4 millimeters, while the tenth ring measures 10.4 millimeters. The use of specialized clothing is allowed to improve the stability of the shooting positions. Qualification round: During the qualification round every 50m Rifle 3 Positions Men competitor has to fire 40 kneeling shots, 40 prone shots and 40 standing shots within a total of 2 hours and 45 minutes. The qualifications are scored in integer points, with the maximum score per shot being 10 points, and the maximum qualification score being 1200 points. Final round: The top eight athletes from the qualification phase advance to the final match, where they can shoot up to 45 final shots. The maximum score for each shot is 10.9 points, because of an additional set of 10 rings within the 10-point circle that increases the score of 0.1 points as it approaches the center of the target. This sets the highest possible score at 490.5 points. The eight finalists start the match with 0 points: the qualification score is not carried forward into the final round. The final begins with three series of 5 shots in the kneeling position to be fired within 200 seconds, followed by a 7 minutes changeover time. Three more series of 5 shots in the prone position are then fired within 150 seconds, followed by a second interval of 9 minutes. Two series of 5 shots open the standing position phase of the match, at the end of which the two lowest aggregate score is eliminated from the final, placing 7th and 8th. The 5 final single shots are fired on command and within 50 seconds, with any following elimination determined by every shot until the Gold and Silver medalists are decided by the 45th and conclusive shot. If there is a tie for the lowest ranking athlete to be eliminated, the tied athletes will fire additional tie-breaking single shots until the tie is broken.

\title{
Objectives of the Study:
}

* To assess the level of focus regulation on archers in Pune city.

* To find out the status of focus regulation on rifle shooters in Pune city.

* To compare the level of focus regulation among archers and rifle shooters in Pune city.

\section{Methodology:-}

Selection of Subjects:-

Random sampling method was used for the better representation of the whole population for the present study.

\author{
Inclusion criteria:- \\ * Only archers and rifle shooters were included. \\ * The athlete whose age was above 23 and below 25 years was included. \\ * Only 40 male athletes (20 archers and 20 rifle shooters) were included. \\ * An elite state level player was included for the study. \\ Sample:-
}

The researcher was selected 40 male athletes as the sample from Shree Chhatrapati Shivaji Sports Complex, Balewadi, Mahalunge, Pune.

\section{Variables:-}

* Focus regulation.

Tools used:-

* Regulatory Focus Questionnaire.

\section{Analysis And Interpretation Of Data:-}

The statistical analysis of data pertaining to the study was collected on 40 (20 archers and 20 rifle shooters) male athletes of Pune city, Maharashtra. The researcher was selected focus regulation as the variable of the study. The standard questionnaire was used for the study of focus regulation among archers and rifle shooters. The "Regulatory Focus Questionnaire" was constructed by Higgins (1997) which is comprised of 11 questions. Independent t-test was applied to find out the significance difference between the groups among archers and rifle shooters on focus regulation variable \& the level of significance was set at 0.05 .

Table 01:- Computation of t-ratio for focus regulation among archers and rifle shooters

\begin{tabular}{|l|l|l|l|l|l|}
\hline Athletes & Mean & N & Std. Deviation & Std. Error Mean & t- ratio \\
\hline Archers & 33.4000 & 20 & 1.69830 & .37975 & \multirow{2}{*}{$0.001093^{*}$} \\
\hline Rifle shooters & 31.4500 & 20 & 2.03845 & .45581 & \\
\hline
\end{tabular}




\section{Significant at 0.05 levels:-}

Tab.05 (19) $=2.093$

From the table-01, the calculated t-value (0.001093) is lesser than tab. T-value (2.093). So, the there was no significant difference between archers and rifle shooters in Pune city.

Graphical representation of focus regulation among archers and rifle shooters

\section{ARCHER (BLUE) AND RIFLE SHOOTER (RED):-}

The graphical representation says that there was no significant difference between archers and rifle shooters in Pune city.

\section{Discussion Of Findings:-}

The study reveals that there was no significance difference among. Both the athlete have great focus on aiming their view and score. Both of them are cooled mind game to win the match. Archer have very sensitive eye that it is play in outdoor and rifle shooting is basically play in indoor. They are all focus on their brain, eye and hand. So, the result ensures that they have similar in focus regulations.

\section{Conclusion:-}

* There was no significance difference among archers and rifle shooters.

* Both athletes are very sensitive on eye, hand and brain coordination.

\section{Recommendations:-}

* Similar study may be conducted by taking other variables than those selected for the purpose of the above study.

* The findings of the study should be given due consideration while selecting players for specific positions of archers and rifle shooter in Pune city Zone.

* Similar study may also be conducted by taking subjects of different age group than those selected for the purpose of the above study.

* The similar study may be conducted only female players in Pune city Zone.

\section{References:-}

1. https://www.olympic.org/archery

2. http://www.asaarchery.com/IP/index.php/tournament-info/rules

3. http://www.issf-sports.org/theissf/championships/olympic_games.ashx

4. https://en.wikipedia.org/wiki/Archery

5. Higgins et al. (2001). "Achievement orientations from subjective histories of success: Promotion pride versus prevention pride". European Journal of Social Psychology, 31. 